\title{
A PARCERIA COM O SISTEMA "S" NA REDE ESTADUAL DO RIO GRANDE DO SUL: INVESTIDA PARA A IMPLANTAÇÃO DE UM PROJETO EDUCATIVO VOLTADO PARA O MERCADO
}

\author{
Renata Cecilia Estormovski ${ }^{1}$
}

\begin{abstract}
Resumo: O propósito deste estudo é analisar a parceria estabelecida entre a Secretaria Estadual de Educação do Rio Grande do Sul e SESI (Serviço Social da Indústria), SENAI (Serviço Nacional de Aprendizagem Industrial) e SENAC (Serviço Nacional de Aprendizagem Comercial) para oferecer cursos profissionalizantes a alunos e profissionais da rede. Relacionando-a a outras iniciativas do governo Sartori, pretende-se mostrar como tais políticas colaboram para a invasão de valores de mercado na educação. Para isso, foi realizada uma análise de conteúdo, em uma perspectiva qualitativa, que examinou informaçóes disponibilizadas em plataformas do governo sobre a proposta. Foi possível compreender, assim, a relação da cooperação em questão com as políticas anteriores que a embasam, percebendo-as como norteadas pela Terceira Via, corrente que incentiva as relaçóes público-privadas. Dessa forma, por meio de iniciativas que refletem o quase-mercado e a propriedade pública nãoestatal, o Estado propóe políticas que o desresponsabilizam de suas obrigaçóes e as repassam para outras entidades, como no caso analisado, favorecendo a implementaçáo de um projeto educativo voltado para o mercado, colaborando com o capital.
\end{abstract}

Palavras-chave: Políticas educacionais. Parceria público-privada. Governo Sartori. Sistema "S". Educação para o mercado.

\section{THE PARTNERSHIP WITH THE SISTEMA “S" IN THE STATE OF RIO GRANDE DO SUL: ATTEMPT TO IMPLEMENT A EDUCATIONAL PROJECT DIRECTED TO THE MARKET}

\begin{abstract}
The purpose of this study is to analyze the partnership established between the State Department of Education of Rio Grande do Sul and SESI (Social Service of Industry), SENAI (National Service of Industrial Learning) and SENAC (National Service of Commercial Learning) to offer vocational courses to students and network professionals. Relating it to other Sartori government initiatives, it is intended to show how such policies collaborate in the invasion of market values in education. For this, a content analysis was carried out, in a qualitative perspective, that examined
\end{abstract}

1 Professora da Rede Estadual de Ensino, especialista em Gestão Educacional (UFSM) e graduada em Letras (FAPLAN) e Pedagogia (UFSM). 
information made available on government platforms on the proposal. It was possible to understand the relation of the cooperation in question with the previous policies that support it, perceiving them as guided by the Third Way, a current that encourages public-private relations. Thus, through initiatives that reflect quasi-market and non-state public ownership, the State proposes policies that disengage it from its obligations and pass it on to other entities, as in the case analyzed, favoring the implementation of an educational project to the market, collaborating with the capital.

Keywords: Educational policies. Public-private partnership. Sartori Government. Sistema "S". Education for the market

\section{INTRODUÇÃO}

Um dos termos mais utilizados atualmente quando se trata de políticas públicas, principalmente se voltadas ao social, é "parceria". A situação considerada como de crise impulsiona medidas que, motivadas pelo argumento do Estado de que não há dinheiro suficiente para manter suas obrigações, buscam compartilhar responsabilidades até então tidas como públicas. Nesse contexto, terceirizações são comuns, bem como convênios e termos de cooperação que objetivam, com essas parcerias, obter um alento para governos que se dizem sem alternativas diante da recessão econômica.

No Rio Grande do Sul, a dívida pública do estado colabora com o cenário de crise orquestrado nacionalmente, incidindo, assim, sobre a população, que sofre os efeitos danosos de um estado que se autointitula sem condições de prover minimamente os direitos sociais dos cidadãos. Dessa forma, recursos repassados com atraso levam até mesmo hospitais à beira do caos, bem como todos os outros setores sociais, que se encontram em dificuldades. $\mathrm{O}$ funcionalismo, sem reajuste há anos e com o $13^{\circ}$ salário de 2016 tendo sido pago em 12 parcelas, está recebendo há meses seus salários de modo atrasado e parcelado e não possui segurança sobre seu próximo vencimento, mesmo diante de sucessivas manifestações e greves, que não obtêm respostas favoráveis à sua situação. Ainda, diferentes projetos buscam repassar as responsabilidades públicas com a educação para o Terceiro Setor e para a iniciativa privada, como o Programa Escola Melhor: Sociedade Melhor, que possibilita publicidade nas instituições educativas em troca de doações, reformas e ampliações; e o Projeto de Lei 44/2016, que pretende qualificar como organizações sociais entidades sem fins lucrativos para que façam a gestão de escolas públicas e também de outros setores.

Colaborando com o cenário exposto, no final do mês de setembro de 2017 , o secretário de educação do Rio Grande do Sul, Ronald Krummenauer, ao lado do governador, José Ivo Sartori, anunciou com entusiasmo uma parceria com entidades do Sistema "S" a fim de oferecer formação profissional a alunos e profissionais da educação. Sem detalhes sobre questões financeiras que envolvam a parceria, mas antecipando que os cursos serão oferecidos na modalidade a distância pelo SESI (Serviço Social da Indústria), pelo SENAI (Serviço Nacional de Aprendizagem Industrial) e pelo SENAC (Serviço Nacional de Aprendizagem Comercial), representantes do governo enfatizaram o caráter gratuito da proposição 
e a possibilidade de que diferentes faixas etárias realizem a formação. Medida semelhante já havia sido proposta em nível federal durante o governo do presidente Luiz Inácio Lula da Silva, quando houve um acordo de gratuidade para estudantes com quatro instituições do Sistema "S": SESC, SESI, SENAI e SENAC. A partir dele, decretos presidenciais como o de $\mathrm{n}^{\circ}$ 6.635, de 5 de novembro de 2008, voltado especificamente para o SENAI, tratavam da oferta de cursos e programas de educação profissional para estudantes trabalhadores ou de baixa renda.

Diante desse contexto, assim, este estudo busca investigar a intencionalidade de tal convênio, articulando-o às demais iniciativas citadas do governo Sartori (2015-2018) para a educação, e analisar como se associam de forma a colaborar para que um projeto educativo voltado às expectativas do mercado seja implantado. Para tanto, este artigo se valerá de uma metodologia de base qualitativa em que, por meio de uma análise de conteúdo, notícias envolvendo o convênio citado - disponibilizadas nas páginas oficiais do governo - serão discutidas, sendo relacionadas às propostas anteriores e debatidas diante do referencial teórico que envolve Peroni (2013; 2016) e Mészàros (2008), entre outros.

\section{PERCURSO METODOLÓGICO}

A fim de compreender a iniciativa investigada neste estudo e analisar de forma adequada os textos "Parceria assegura 12,4 mil vagas em cursos $\mathrm{EaD}$ para alunos e professores" (publicada em 28 de setembro de 2017 no site da Secretaria do Desenvolvimento Econômico, Ciência e Tecnologia) e "Veja como vai funcionar o convênio para alunos e professores da rede estadual com o Sistema S" (acessível a partir do dia 03 de outubro de 2017 na página da Secretaria de Educação) que a abordam, optou-se por se utilizar uma análise de conteúdo. Essa metodologia, usada principalmente em pesquisas qualitativas - nas quais esta se insere -, foi sistematizada por Bardin e publicada em 1977, apesar de já ser empregada anteriormente. Como define Câmara, na análise de conteúdo:

[...]o pesquisador busca compreender as características, estruturas ou modelos que estão por trás dos fragmentos de mensagens tornados em consideração. O esforço do analista é, então, duplo: entender o sentido da comunicação, como se fosse o receptor normal, e, principalmente, desviar o olhar, buscando outra significação, outra mensagem, passível de se enxergar por meio ou ao lado da primeira. (CÂMARA, 2013, p. 182)

Assim, buscou-se aguçar o olhar para as descrições e os discursos contidos nas informações sobre o acordo, almejando depreender dali significados contextualizados que retratassem os objetivos da parceria, relacionando-a com projetos anteriores da equipe de governo. Dessa forma, seguindo o percurso definido por Bardin e citado por Câmara (2013), inicialmente o material foi organizado e pré-analisado; em seguida, foi explorado, sendo codificado, classificado e categorizado; posteriormente, houve sua contextualização diante das políticas para, enfim, interpretá-lo, inferindo resultados e relacionando-os à bibliografia. 
A semântica teve um papel de destaque durante a pesquisa, como antecipado por Campos (2004, p. 612), pois é dela que se depreenderam os sentidos do texto, que fizeram com que, por intermédio da análise de conteúdo, as publicações pudessem ser decifradas e analisadas, favorecendo sua inferência e interpretação.

\title{
AS POLÍTICAS DA DÉCADA DE 1990 E A TERCEIRA VIA: REGULAMENTAÇÓES PARA PARCERIAS PÚBLICO-PRIVADAS
}

Por mais que sejam facilmente identificadas nas políticas estaduais propostas pelo governo Sartori, que serão analisadas neste estudo, as proposições voltadas ao repasse de compromissos estatais para a iniciativa privada e para o Terceiro Setor estão enraizadas nas políticas públicas brasileiras, em especial nas da década de 1990. Num cenário em que a crise também era tida como incontestável e com o seu diagnóstico inculcado ao próprio Estado (como típico no ideário neoliberal citado por Peroni, 2016), diferentes aparatos legais foram concebidos nessa década, como o Plano Diretor da Reforma do Aparelho do Estado. Lançado em 1995 pelo Ministério da Administração Federal e Reforma do Estado, o documento propõe, já de início, uma administração pública gerencial:

\begin{abstract}
[...] baseada em conceitos atuais de administração e eficiência, voltada para o controle dos resultados e descentralizada para poder chegar ao cidadão, que, numa sociedade democrática, é quem dá legitimidade às instituições e que, portanto, se torna "cliente privilegiado" dos serviços prestados pelo Estado (MARE, 1995, p.7).
\end{abstract}

Argumentando sobre a ineficiência do Estado até então, propõe-se que seu papel seja redefinido, alterando-o de executor de serviços para o de regulador e promotor do desenvolvimento, repassando "para o setor privado as atividades que podem ser controladas pelo mercado" (p. 12). Incentivando privatizações e publicizações - transferências da execução de serviços que necessitam de subsídio, mas não de poder do Estado, para o setor público não-estatal-, abriu possibilidades para que a lógica econômica se fortalecesse nos serviços públicos. O documento, ainda, favoreceu legislações posteriores que ratificaram seus princípios, como é o caso da Lei Federal 9.637/1998, que regularizou a qualificação de organizações sociais em nível nacional, criou o Programa Nacional de Publicização e extinguiu órgãos e entidades, entre outros apontamentos.

Esses dois dispositivos da década de 1990, em específico, amparam muitas das legislações atuais, que buscam, bem como na época, favorecer a desresponsabilização do poder público diante das políticas sociais. Em março de 2017 o governador José Ivo Sartori, por exemplo, instituiu, recorrendo ao Decreto $n^{\circ}$ 53.495, o Programa de Concessões e de Parcerias Público-Privadas Estado do Rio Grande do Sul, e seu Conselho Gestor, a ser composto exclusivamente pelos secretários do governo, pelo próprio governador e por pessoas por ele indicadas. Conforme disposto no Artigo $1^{\circ}$, parágrafo $1^{\circ}$, o decreto volta-se aos “órgãos da Administração Pública Estadual direta, aos fundos especiais, às autarquias, às fundações públicas, às empresas públicas, às sociedades de economia mista e às 
demais entidades controladas direta ou indiretamente pelo Estado". Por meio de medidas legislativas austeras e pouco democráticas como essa, diferentes governos regulamentam a invasão do que deveria ser considerado público por ideais de mercado, tornando as fronteiras entre esses dois segmentos cada vez mais flexíveis e permeáveis.

Essas iniciativas fazem parte das redefinições do papel do Estado e das estratégias voltadas às alterações da relação público-privado no que Peroni (2016) afirma ser um período particular do capitalismo. Segunda a autora:

As mudanças nas fronteiras entre o público e o privado têm se modificado neste período de crise do capitalismo, em que as suas estratégias de superação - neoliberalismo, globalização, reestruturação produtiva e Terceira Via redefinem o papel do Estado, principalmente para com as políticas sociais. (PERONI, 2016, p. 68)

A Terceira Via, assim, se destaca como uma das principais estratégias utilizadas pelos governantes por possibilitar reformas que são aceitas facilmente pela população na medida em que não abdicam, aparentemente, de sua propriedade. Isso acontece porque, apesar de a Terceira Via e o Neoliberalismo compartilharem o mesmo diagnóstico de que a crise é causada pelos excessos do Estado e busquem diminuir, dessa maneira, o papel do poder público, atuam de formas distintas: enquanto o Neoliberalismo propõe a privatização, a Terceira Via defende as terceirizações, que se dão principalmente com a busca de parcerias (PERONI; OLIVEIRA; FERNANDES, 2009). Tais parcerias são regularizadas pelos artefatos legais da década de 1990 citados, que consequentemente amparam os atuais, e são encaradas pelos cidadãos como alternativas amenas e, muitas vezes, necessárias diante da crise.

Quanto à crise, é importante considerá-la como do capital e estrutural, como Peroni e Caetano (2016) apontam citando Mészàros, considerando-se que possui "caráter universal, não estando restrito a uma esfera particular financeira ou comercial; seu escopo é global e não atinge apenas um ou outro país; e sua escala de tempo é extensa e contínua e não é limitada ou cíclica, como as crises anteriores do capital" (PERONI; CAETANO, 2016, p. 409). Dessa forma, restringi-la a um reflexo de má gestão pública, tomando o Estado como seu causador, mostra-se como uma visão muito restrita de um fenômeno amplo, complexo e histórico. No entanto, o diagnóstico da crise como reflexo de gastos exagerados em políticas sociais e de interferência do Estado na economia define as políticas públicas e afeta diretamente a maneira com que a relação entre o público e privado se dá, especialmente num contexto em que a Terceira Via se salienta como uma de suas alternativas.

Para que seja implementada, a Terceira Via se utiliza de dois movimentos: o setor público não-estatal e o quase-mercado, como explicado por Peroni (2013). Com o público não-estatal, há uma redefinição da propriedade que deixa de ser pública e passa a ser pública de direito privado, como é o caso das parcerias entre o poder público e entidades do Terceiro Setor, em que se incluem as organizações 
sociais. Já o quase-mercado "altera a lógica do público, introduzindo concepções de gestão privada nas instituições públicas sem alterar a propriedade das mesmas" (PERONI; CAETANO, 2016), tendo-se em vista que a Terceira Via, que continuamente aproxima-se da concepção neoliberal, também crê que a lógica mercantil na gestão é mais produtiva e eficiente do que a pública.

Como será destacado a seguir, tais pressupostos são perceptíveis nas políticas propostas no Rio Grande do Sul entre 2015-2017. Com iniciativas que buscam repassar as escolas da rede para as organizações sociais, que regulamentam parcerias das instituições educativas com empresas e, como tratado especificamente por esse trabalho, que direcionam a responsabilidade de formação discente para o Sistema "S", o Governo Sartori mostra-se alinhado com a Terceira Via. Utilizando-se tanto do quase-mercado, quanto da propriedade pública não-estatal, suas proposições articulam-se rumo a uma formação destituída de criticidade, cidadania e significação histórica e social, restringindo-se apenas a contemplar as expectativas do mercado.

\section{ANÁLISE E DISCUSSÃO DA PARCERIA COM O SISTEMA “S” E SUA INTERLOCUÇÃO COM AS POLÍTICAS PÚBLICAS EDUCACIONAIS NO RIO GRANDE DO SUL ENTRE 2015-1017}

Desde o início da gestão do governador Sartori, em 2015, a retórica da crise alimenta os discursos, sendo que a quitação da folha salarial em dia tem sido uma grande dificuldade, bem como o pagamento da parcela da dívida do estado com a União. Aliados a tais empecilhos, aumentos salariais e promoções não estão sendo concedidos, sendo que os salários dos servidores e os repasses às escolas têm sido parcelados ou pagos com atrasos. $\mathrm{O}$ mesmo acontece com o provimento das demais áreas sociais, que têm sido levadas a condições de extrema necessidade devido aos escassos recursos. Ainda, terceirizações, fechamento de fundações e a busca por privatizações têm sido corriqueiras, bem como atos públicos e greves, que buscam preservar direitos que dia a dia vêm sendo ameaçados, mas que não têm obtido o resultado esperado pela falta de diálogo e também de empatia do governo.

Aliados a isso, diferentes Projetos de Lei do Poder Executivo buscam efetivação, dando forma a um projeto de diminuição dos direitos dos trabalhadores estaduais, de mercantilização de serviços e entidades e de sucateamento do que permanece sob responsabilidade estatal. $\mathrm{Na}$ educação, dois projetos descrevem a busca pela desresponsabilização do estado com a manutenção de seus serviços: o PL 103/2015, que foi aprovado e deu origem ao Programa Escola Melhor: Sociedade Melhor; e o PL 44/2016, que ainda não foi posto em votação, já que se encontra parado na Comissão de Constituição e Justiça. O primeiro regulariza parcerias de escolas estaduais com pessoas físicas e jurídicas a fim de que estas realizem reformas, ampliações, instalações de redes wi-fi e doações às escolas, retirando do governo estadual, dessa maneira, a responsabilidade com a manutenção das instituições escolares. Em troca, pode-se realizar publicidade dentro das escolas, o que ocorre com a pintura de um muro ou com a colocação de uma placa. O Programa Escola Melhor: Sociedade Melhor, evidencia a inserção do quase-mercado nas instituições 
educativas estaduais, pois regulamenta, sob a égide da lógica mercantil, as trocas de benefícios entre escolas e empresas ou pessoas físicas por meio de uma venda, mesmo que velada e mascarada, de publicidade dentro das instituições escolares. Assim, favorece o consumo e a competição empresarial dentro dos ambientes escolares, interferindo nos valores da comunidade escolar. Esse projeto leva à inserção de valores de mercado na instituição, estimula o consumo e a concorrência e acirra desigualdades, na medida em que escolas que não conseguirem tais parcerias ficam desassistidas pelo governo, sendo ignoradas em suas necessidades.

O PL 44/2016 é ainda mais agressivo, já que busca a qualificação de entidades de direito privado e sem fins lucrativos como organizações sociais, possibilitando que associações alheias à comunidade recebam recursos públicos para gerir as instituições não só educacionais, mas de diferentes áreas, como a pesquisa científica, a saúde, o esporte e o meio ambiente. O Projeto de Lei, que descreve os prérequisitos das associações que pretendem se qualificar, como deve ser a composição do Conselho de Administração, as normas do Contrato de Gestão e sua execução e também o fomento das atividades e o processo de desqualificação, não esclarece como se dará a inclusão destas entidades no serviço público. Sem pormenores que tragam de forma nítida essa compreensão, no entanto, na educação o projeto parece seguir o modelo americano das charter schools, que tem se popularizado e trazido muita discussão no Brasil nos últimos anos, implementando o que Peroni (2013) cita como propriedade pública não-estatal. O caso mais debatido, que envolve a rede estadual de Goiás, teve seu edital de chamamento de organizações sociais suspenso pela justiça em 2016 após intensos protestos dos movimentos estudantis e dos docentes. Como indicam Souza e Flores (2017), proposições como essa trazem alta lucratividade para as associações tidas como de Terceiro Setor que passam a receber repasses do Poder Público -, alteram a forma de contratação de professores e também descumprem o Plano de Carreira e a Lei do Piso Salarial Nacional da categoria. Além disso, põe-se em risco a gestão escolar democrática, já que entidades alheias à comunidade passam a comandar as tomadas de decisão, e o trabalho pedagógico passa a ser influenciado por entidades que possuem a gestão gerencial como bandeira, subordinando a educação à lógica do mercado.

Dando prosseguimento a tais projetos voltados à educação, em 28 de setembro de 2017, a Secretaria de Educação do estado do Rio Grande do Sul assinou um termo de cooperação, com duração de 18 meses, com SESI, SENAI e SENAC, disponibilizando, inicialmente, 10 mil vagas para estudantes em cursos técnicos e 2.414 vagas para docentes e demais profissionais da área no curso de Gestão para Educação de Qualidade. De acordo com os textos "Parceria assegura 12,4 mil vagas em cursos EaD para alunos e professores" (disponível no site da Secretaria do Desenvolvimento Econômico, Ciência e Tecnologia e datada de 28 de setembro de 2017) e "Veja como vai funcionar o convênio para alunos e professores da rede estadual com o Sistema S" (postado na página da Secretaria de Educação em 03 de outubro de 2017), todos os cursos serão oferecidos na modalidade a distância e sinalizam apenas a parte introdutória de uma parceria que pretende ser aumentada pelo governo, com o alcance de 100\% dos profissionais da 
educação no ano de 2018 e com a expansão do acordo com o Serviço Nacional de Aprendizagem Rural (SENAR) e o Serviço Brasileiro de Apoio às Micro e Pequenas Empresas (SEBRAE).

Com relação ao convênio com o SENAC, em 2017, um projeto-piloto envolveu a oferta dos cursos de Logística, Qualidade e Recursos Humanos, com 800 horas-aula cada, para as cidades de Canela e Guaíba. Dessa maneira, apenas alunos residentes nestes dois municípios tiveram a possibilidade de inscrição. No entanto, em 2018 serão ofertadas 1.800 vagas para discentes de todo o estado nos cursos de Segurança do Trabalho (1.200 horas), Programação de Jogos Digitais (1.000 horas), Design de Interiores (800 horas), Meio Ambiente (1.200 horas), Administração (1.000 horas), Guia de Turismo (800 horas), Informática (1.200 horas), Logística (800 horas), Recursos Humanos (800 horas), Transações Imobiliárias (960 horas), Marketing (800 horas) e Qualidade (800 horas).

O SENAI oferece 13 cursos por meio do acordo, citados no site da Secretaria de Educação como de "competências transversais", com 14 horas/ aula cada, destinados tanto a alunos quanto a professores. Os cursos são de Educação Ambiental, Consumo Consciente de Energia, Lógica de Programação, Fundamentos da Logística, Metrologia, Noções Básicas de Mecânica Automotiva, Empreendedorismo, Desenho Arquitetônico, Finanças Pessoais, Segurança no Trabalho, Legislação Trabalhista, Tecnologia da Informação e Comunicação e Propriedade Intelectual. Somente podem se inscrever residentes nos municípios em que o SENAI possui representatividade, tendo no mínimo 14 anos e estando matriculados no $9^{\circ}$ do Ensino Fundamental ou no Ensino Médio. A superintendente da Superintendência da Educação Profissional do Estado (SUEPRO), Mara Zuraski, afirmou na matéria disponibilizada no Portal da SEDUC que, o fato de professores também poderem realizar os cursos é positivo, pois possibilita que docentes e discentes discutam em sala de aula as temáticas de uma mesma formação escolhida.

Já o SESI se detém em oferecer o curso de Gestão para Educação de Qualidade, que se destinou, em 2017, aos servidores da SEDUC, da SUEPRO e das Coordenadorias Regionais de Educação, e será expandido para todos os profissionais da rede em 2018. No site do SESI, o curso é citado como motivador da participação da comunidade escolar na identificação de problemas, no planejamento, na busca por soluções, no monitoramento dos processos e na busca pela melhoria dos indicadores da qualidade da educação.

$\mathrm{Na}$ ocasião da assinatura do termo de cooperação, no dia 28 de setembro de 2017, no Palácio Piratini, conforme consta no site da Secretaria do Desenvolvimento Econômico, Ciência e Tecnologia, Ronald Krummenauer, secretário da Educação, destacou que os cursos são atualizados e buscam a formação profissional, voltandose ao mercado de trabalho. Para ele, a parceria simboliza "o público e o privado unindo esforços e contribuindo para uma educação melhor no Rio Grande do Sul”.

$\mathrm{Na}$ mesma oportunidade, o governador do estado afirmou que:

São capacitações que devem servir para todas as faixas etárias. É acesso a um mínimo de preparação para o mercado de trabalho e para a profissionalização. 
Estamos no início de uma caminhada para a qualidade da educação e da construção de grandes talentos. Uma oportunidade que não pode ser desperdiçada.

A iniciativa, apresentada com discursos otimistas como se representasse inovação, todavia, não é uma proposta autêntica. Luiz Inácio Lula da Silva, enquanto Presidente da República, já havia adotado medida semelhante, firmando parceiras de gratuidade para estudantes trabalhadores ou de baixa renda com SESC, SESI, SENAI e SENAC. No Decreto Presidencial no 6.635, de 5 de novembro de 2008, o convênio com o SENAI foi exposto, destacando o caráter gratuito de cursos e programas de educação profissional para o público citado. Outros decretos semelhantes fizeram alusão às outras entidades do Sistema "S", reforçando a relações entre a esfera pública e entidades empresariais.

Bem como em nível nacional, no Rio Grande do Sul, como destacado no próprio discurso do secretário de educação Ronald Krummenauer durante a assinatura do convênio, a parceria com o Sistema "S" representa uma união de esforços entre o público e o privado, sendo difundida como positiva para a educação. Contudo, a proposição mostra-se de forma explícita como uma forma de quase-mercado, pois por mais que os cursos ofertados sejam realizados de forma paralela aos estudos cursados nas escolas, denota uma tentativa notória de alinhar os discentes a uma educação voltada às expectativas do mercado, na medida em que se direcionam, especificamente, à educação profissional. Ao esmiuçar os discursos quando da apresentação do projeto de parceria com entidades do Sistema "S", vários indícios apontam um direcionamento das políticas para o acolhimento dos interesses do capital. Como percebido nas falas do secretário e do governador, a preocupação central dessa proposta é profissionalizar, fazendo com que os alunos, ao encerrarem a etapa de escolarização básica, já possuam habilidades técnicas que possam ser oferecidas ao mercado.

Também é importante que se destaque, na fala do governador, a preocupação com a qualidade da educação. Cabe-se questionar aqui, no entanto, qual o conceito de qualidade que está subentendido nesse discurso, considerando-se a semântica variada que pode ser contida nesse termo. Mas analisando as especificidades do curso Gestão para Educação de Qualidade, a ser realizado por docentes e demais profissionais da educação, há uma pista: o curso busca melhorar os indicadores educacionais. Então, se bons resultados em avaliações serão tidos como sinônimo de qualidade, compreende-se que a lógica tão colaborativa com uma educação voltada aos mercados será a norteadora também nesse aspecto. Como traz Souza (2009), os indicadores educacionais refletem um formato de avaliação que não privilegia o processo, mas apenas os resultados, os produtos, mensurando e ranqueando alunos e escolas, e tornando-se instrumento de controle. As avaliações externas, nas quais se baseiam esses indicadores, refletem uma proposta neoliberal, já que "é marcada por uma ideia reguladora: a da privatização; baseada na defesa da competência, na eficiência da iniciativa privada e na sua superioridade em relação às ações públicas, coletivas" (SOUZA, 2009, p. 19). Portanto, o conceito de qualidade da educação almejado é bastante restrito, na medida em que envolve o alcance de uma posição 
privilegiada nos rankings e não implica, necessariamente, em um desenvolvimento amplo dos potenciais discentes, de forma humanizadora, crítica e libertadora.

Outro aspecto que precisa ser destacado é que, quando se sugere que docentes e discentes compartilhem essa "oportunidade" de formação (usando o mesmo termo utilizado pelo governador), notam-se as intenções de disseminação do projeto. O papel multiplicador do professor pode intensificar os conteúdos tratados em determinado curso, replicá-los e, ainda, incentivar a adesão de um número maior de alunos às propostas. Assim, a ação docente em sala de aula se mostra como uma ferramenta para que os objetivos que estão por trás dessa iniciativa sejam mais largamente difundidos, ampliando os impactos dessa parceria.

É importante que essa proposição não seja relacionada ao Ensino Médio Politécnico, proposto pela Secretaria de Educação do Rio Grande do Sul durante o governo de Tarso Genro (2011-2014). Tal iniciativa colocava o trabalho como princípio educativo e, como traz Roos (2015), pretendia discutir as mudanças ocorridas no mundo do trabalho por intermédio de uma formação humana e cidadã. Buscava-se, com esse projeto, significar a função fundamental da escola, tida como "ensinar a compreender e a transformar a realidade, a partir do domínio da teoria e do método científico." (ROOS, 2015, p. 04)

Todavia, o acordo com SESI, SENAI e SENAC, além de se configurar como uma tentativa notória de formar mão de obra, também se torna questionável por fazê-lo de forma precoce, já que, antes mesmo de terminar o Ensino Fundamental, como permite uma das plataformas de cursos disponíveis, os alunos já poderão se alinhar a uma área profissional. Contudo, como traz Ramos (2016, p. 30):

[...]não faz sentido delimitar o horizonte de desenvolvimento humano precocemente, seja pela restrição de sua escolaridade, seja pela determinação seletiva dos tipos de conhecimentos a que o estudante poderá ter acesso, em quantidade e qualidade, pelo lugar ocupado na divisão social do trabalho.

Profissionalizar antes que os jovens tenham tido oportunidade de uma formação ampla, envolvendo diferentes saberes nas diversas áreas do conhecimento, na "totalidade da vida social e produtiva" (RAMOS, 2017, p. 30), restringe suas possibilidades de desenvolvimento. Isso se torna ainda mais grave por ocorrer na rede pública de ensino, responsável pela educação dos filhos dos trabalhadores. Parece haver aí o reforço da dicotomia que vem se buscando superar há muitas décadas e que envolve a ideia de que os filhos do proletariado não podem almejar mais do que arrumar um bom emprego ao final da escolarização básica, já que o prosseguimento dos estudos é reservado para as classes mais abastadas.

E essa profissionalização se alinha a uma educação escolar precarizada, tendo-se em vista todo o contexto no qual as escolas estaduais estão inseridas: de manutenção precária e, em algumas instituições, terceirizada; de estrutura física deteriorada e sucateada; de profissionais da educação desestimulados pelo fato de nem ao menos terem garantias salarias e por estarem sendo constantemente ameaçados pela extinção de direitos. Todas essas questões acabam interferindo na educação construída e, mesmo que não de forma intencional, prejudicando seu 
desenvolvimento voltado à criticidade, à formação humanizadora e integral, que poderia questionar e problematizar o ensino profissional paralelamente oferecido.

Dessa forma, unindo os aspectos citados, pode-se perceber que a parceria com o Sistema "S" colabora com o mercado, fazendo da educação da rede pública um instrumento para que as expectativas desse setor sejam alcançadas por meio da formação de mão de obra, mas não somente disso. Também implica na inserção da lógica gerencial como norteadora dos conceitos educativos, como o quasemercado bem explica, criando uma subjetividade que a favoreça, em um processo de precarização do serviço público e de fortalecimento do capital.

Logo, a inciativa do governo em estabelecer parcerias com o Sistema "S" também mostra-se relacionada ao PL 44/2016 e ao Programa Escola Melhor: Sociedade Melhor já que todos revelam, de um viés diferente, a tentativa do estado em desresponsabilizar-se de suas obrigações com os serviços públicos, repassando a parceiros suas obrigações. Afinal, por intermédio da parceria com o grupo em questão, o governo delega a outrem parte da formação de seus alunos, deixando de investir na melhoria da educação oferecida dentro de sua rede.

\section{AS INICIATIVAS DO GOVERNO SARTORI COMO UM PROJETO DE EDUCAÇÃO VOLTADA PARA O MERCADO}

Como buscou-se elucidar, a cooperação assinada entre a Secretaria Estadual de Educação e SESI, SENAI e SENAC possui, em sua intencionalidade, elementos que mostram sua relação com interesses econômicos. Mas a iniciativa citada, como vem se tentando mostrar na extensão deste artigo, não pode ser analisada isoladamente, pois se articula aos demais projetos propostos pelo governo Sartori entre 2015 e 2017, especificamente o Programa Escola Melhor: Sociedade Melhor e o PL 44/2016. A parceria com entidades do Sistema "S" se salienta como parte de um empreendimento mais amplo do governo, buscando implantar na rede estadual um projeto educativo identificado com as expectativas do mercado. Afinal, com as escolas sendo mantidas por pessoas físicas e jurídicas e geridas por organizações sociais (etapa ainda não realizável já que esse projeto não foi aprovado até a publicação deste texto), resta apenas a formação de mão de obra durante a escolarização básica para se ter uma educação para o capital. Coopera com isso o cenário de pleno abandono do estado com as escolas e com o funcionalismo, o que desmotiva professores e demais profissionais, colocando em risco o fazer pedagógico e enfraquecendo seus projetos educativos. A lógica do setor privado, assim, é inserida cotidianamente por meio da publicidade e dos ideais da gestão gerencial, que influenciam os processos de participação, os valores comunitários, a autonomia financeira, as tomadas de decisão e o próprio conteúdo da educação. O setor público, cada vez mais precarizado e enfraquecido, apenas reforça o ideário que afirma sua ineficiência, fortalecendo as iniciativas que buscam sua condenação.

Dessa forma, aos poucos um projeto de educação que satisfaz o desejo de uma sociedade capitalista vai se construindo. Como discute Mészàros (2008, p. 25), "os processos educacionais e os processos sociais mais abrangentes de reprodução 
estão intimamente ligados". Assim, qualquer mudança na educação implica, necessariamente, em alterações na sociedade. No momento em que a educação não é vista nem buscada como instrumento de emancipação humana, mas concebida como ferramenta para a formação de mão de obra e, principalmente, como forma de legitimização e de internalização de seus valores, são os interesses das classes dominantes, detentoras do capital, que são atendidos. Então, a subjetividade que é produzida também acaba por impedir a condenação ao sistema instaurado, reiterando-o como única alternativa plausível de desenvolvimento, mesmo com suas consequentes desigualdades e opressões sendo tão perceptíveis. A educação torna-se mecanismo não apenas de abastecimento desse sistema, mas garante sua perpetuação por meio de processos de internalização de seus pressupostos.

Como discutem Oliveira e Almeida (2009), em iniciativas como as abordadas neste artigo:

A ideia da educação tem apenas um caráter mercadológico, aliada a uma
visão imediatista, pela qual os resultados precisam aparecer a curto prazo.
O desenvolvimento humano passa a ser visto como mais um número, sem
considerar o contexto social, as interferências culturais e políticas e, ainda
pior, sem uma ação efetiva de emancipação. (OLIVEIRA; ALMEIDA, 2009,
p. 158)

Os processos formativos, nesse cenário, voltam-se à obtenção de qualificações esperadas pelo mercado, alcançadas na maior quantidade possível e de modo precoce como forma de se buscar garantias de inserção em mundo marcado pela competição e pela possibilidade de que, no contexto de crise do capital orquestrada, não haja espaço para todos. Dessa forma, o governo oferece aos alunos a possibilidade de instrumentalização a curto prazo e de forma precoce como possibilidade de que não sejam atingidos por tais danos. À indústria especificamente, e ao mercado como um todo, garante-se mão de obra especializada para atuação imediata. Isso, no entanto, acaba retirando do percurso educativo dos discentes perspectivas de uma educação emancipadora, contextualizada e cidadã.

Dessa maneira, a iniciativa da Secretaria de Educação em estabelecer parcerias com o Sistema "S" precisa entendida dentro desse contexto, como mais uma investida do governo para concretizar na rede estadual uma educação voltada ao favorecimento do mercado. Junto ao Programa Escola Melhor: Sociedade Melhor e ao PL 44/2016 (que ainda não se efetivou, mas que possui possibilidades de aprovação), a cooperação assinada colabora com os interesses do capital, motivando a formação de mão de obra e de uma subjetividade que fortalece a lógica privada e a reforça, consolidando o próprio capitalismo.

\section{CONSIDERAÇÓES FINAIS}

No decorrer deste estudo, buscou-se analisar a parceria assinada entre governo do estado do Rio Grande do Sul, por meio de sua Secretaria de Educação, com entidades do Sistema "S". Voltada à profissionalização dos discentes da rede (antes mesmo da conclusão do Ensino Fundamental em um dos casos), a parceria 
denota inter-relação com a Terceira Via, corrente que, recorrendo ao quasemercado e à propriedade pública não-estatal, busca delegar à iniciativa privada e a entidades do Terceiro Setor a manutenção de suas atividades. No caso em questão, a parceria se relaciona a outras duas que foram propostas anteriormente: uma em que a manutenção das escolas pode ser delegada a pessoas físicas ou jurídicas em troca de publicidade, e outra em que se objetiva qualificar entidades como organizações sociais para gerir as instituições escolares. Unindo as três proposições, que se ancoram no argumento de crise do estado, percebe-se a tentativa de se implementar um projeto educativo que vá ao encontro das expectativas do mercado. Com a formação de mão de obra precoce, aliada a uma escola e a professores abandonados e reféns de uma situação em que dependem de entidades externas para manter e gerir suas escolas, com recursos e salários defasados e atrasados e, consequentemente, com sua prática pedagógica se enfraquecendo, a educação humanizadora, dia a dia, perde suas possibilidades de se concretizar. Além disso, os valores externos impactam sobremaneira o cotidiano, impondo a lógica da gestão privada que, em um contexto de educação mercantilizada, como citado por Mészàros (2008), somente reforça o próprio capital e a exploração de classe imposta por ele.

Ao analisar essas propostas, contudo, pode parecer que o objetivo deste artigo é unicamente criticar todas as ações do governo que buscam alterar a educação, como se o status da mesma fosse satisfatório. Mas, pelo contrário, sabe-se que a educação oferecida pela rede estadual gaúcha tem muito a melhorar, no entanto, as tratativas do governo apenas a desqualificam ainda mais, dificultando a construção de um processo educativo humanizado, libertador e crítico. Como Mészàros (2008) cita, "limitar uma mudança educacional radical às margens corretivas interesseiras do capital significa abandonar de uma só vez, conscientemente ou não, o objetivo de uma transformação social qualitativa". É necessário eliminar "os fundamentos causais antagônicos e profundamente enraizados" (p. 26) do capital, confrontando "todo o sistema de internalização, com todas as suas dimensões, visíveis e ocultas", para que realmente a mudança na educação (e na sociedade, visto que são indissociáveis) aconteça, já que o capital é irreformável. (MÉSZÀROS, 2008, p. 47)

\section{REFERÊNCIAS}

BRASIL. Decreto $\mathrm{n}^{\circ}$ 6.633, de 5 de novembro de 2008. Altera e acresce dispositivos ao Regulamento do Serviço Nacional de Aprendizagem Comercial - SENAC, aprovado pelo Decreto no 61.843, de 5 de dezembro de 1967. Disponível em: <http://sitesistec.mec.gov.br/images/stories/pdf/decreto_6633_2008.pdf>. Acesso em 18 dez. 2017.

BRASIL, Ministério da Administração e Reforma do Estado (MARE). Plano Diretor da Reforma do Aparelho de Estado. Brasília, 1995. Disponível em: <www.bresserpereira. org.br>. Acesso em: 02 out. 2017. 
CÂMARA, R.H. Análise de conteúdo: da teoria à prática em pesquisas sociais aplicadas às organizações. Gerais: Revista Interinstitucional de Psicologia, v. 6, n. 2, p. 179-191, jul/dez. 2013. Disponível em: < http://pepsic.bvsalud.org/pdf/gerais/v6n2/v6n2a03. pdf>. Acesso em: 05 out. 2017.

CAMPOS, C. J. G. Método de Análise de Conteúdo: ferramenta para a análise de dados qualitativos no campo da saúde. Revista brasileira de enfermagem, Brasília, v. 57, n.5, 2004, p.611-614. Disponível em: <http://www.scielo.br/scielo.php?pid=S0034$71672004000500019 \&$ script $=$ sci_abstract\&tlng $=$ pt $>$. Acesso em 01 out. 2017.

MÉSZÀROS, I. A educação para além do capital. São Paulo: Boitempo, 2008.

OLIVEIRA, S. A. Z. P.; ALMEIDA, M. L. P. Educação para o mercado x educação para o mundo do trabalho: impasses e contradições. Revista Espaço Pedagógico, Passo Fundo, v. 16, n. 2, p. 155-167, jul./dez. 2009. Disponível em: <http://seer.upf.br/index. $\mathrm{php} / \mathrm{rep} / \mathrm{article} / \mathrm{view} / 2222>$. Acesso em 15 out. 2017.

PARCERIA assegura 12,4 mil vagas em cursos EaD para alunos e professores. SDECT, Porto Alegre, 2017. Disponível em: <http://www.sdect.rs.gov.br/parceria-assegura-12-4mil-vagas-em-cursos-ead-para-alunos-e-professores>. Acesso em 19 dez. 2017.

PERONI, V. M. V. As relações entre o público e o privado nas políticas educacionais no contexto da Terceira Via. Currículo sem Fronteiras, v. 13, n. 2, p. 234-255, maio/ago. 2013. Disponível em: <www.curriculosemfronteiras.org/vol13iss2articles/peroni.pdf>. Acesso em: 11 out. 2017.

PERONI, V.M.V. Relação público-privado na Educação Básica: a democratização da educação? Movimento, Rio de Janeiro, ano 3, n. 5, p. 67-75, 2016. Disponível em: <http://www.revistamovimento.uff.br/index.php/revistamovimento/>. Acesso em: 12 out. 2017.

PERONI, V.M.V.; CAETANO, M.R. Atuação em Rede e o Projeto Jovem de Futuro: a privatização do público. Educação \& Realidade, Porto Alegre, v. 41, n. 2, p. 407-428, abr./jun. 2016. Disponível em: <http:// www.scielo.br/>. Acesso em: 12 out. 2017.

PERONI, V.M.V.; OLIVEIRA, R.T.C.; FERNANDES, M.D.E. Estado e Terceiro Setor: As novas regulações entre o público e o privado na gestão da Educação Básica brasileira. Educ. Soc., Campinas, vol. 30, n. 108, p. 761-778, out. 2009. Disponível em < http:// www.cedes.unicamp.br>. Acesso em: 11 out. 2017.

RAMOS, M.N. Ensino Médio Integrado: Lutas históricas e resistências em tempos de regressão. In: ARAÚJO, A. C.; SILVA, C.N.N. (orgs.). Ensino Médio Integrado no Brasil: fundamentos, práticas e desafios. Brasília: Ed. IFB, 2017.

RIO GRANDE DO SUL. Decreto n ${ }^{\circ}$ 52.605, de 15 de outubro de 2015. Regulamenta a Lei $n^{\circ} 14.734$, de 16 de setembro de 2015, que institui, no âmbito da Secretaria da Educação, o Programa Estadual Escola Melhor: Sociedade Melhor. Diário Oficial do Estado no 198 , de 16 de outubro de 2015.

RIO GRANDE DO SUL. Decreto no 53.495, de 30 de março de 2017. Institui o Programa de Concessões e de Parcerias Público-Privadas Estado do Rio Grande do Sul, e 
o Conselho Gestor do Programa de Concessões e Parcerias Público Privadas, no âmbito da Administração Pública do Estado do Rio Grande do Sul. Diário Oficial do Estado no 062 , de 31 de março de 2017.

RIO GRANDE DO SUL. Lei no 14.734, de 15 de setembro de 2015. Institui o Programa Estadual Escola Melhor: Sociedade Melhor. Diário Oficial do Estado no 177, de 16 de setembro de 2015.

RIO GRANDE DO SUL. Portaria no 316/2015. Define normas e procedimentos para o integral cumprimento do Decreto $n^{\circ} 52.605$, de 15 de outubro de 2015, que regulamenta o Programa Escola Melhor: Sociedade Melhor. Diário Oficial do Estado de 11 de dezembro de 2015.

RIO GRANDE DO SUL. Projeto de Lei $\mathbf{n}^{\circ} 44$ /2016. Dispõe sobre a qualificação de entidades como organizações sociais. Disponível em < http://www.al.rs.gov.br/>. Acesso em: 04 out. 2017.

ROOS, M.M.S. O Ensino Médio Politécnico em uma escola estadual do Rio Grande Do Sul: Uma política pública no contexto da prática. In: $37^{a}$ Reunião Nacional da ANPEd, 2015, Florianópolis. Anais... Florianópolis: UFSC, 2015. Disponível em: <http:// sitesistec.mec.gov.br/images/stories/pdf/decreto_6633_2008.pdf>. Acesso em: 19 dez. 2017.

SOUZA, F. A.; FLORES, M. M. L. Uma análise sobre a implementação das Organizações Sociais nas escolas de Goiás: os recursos públicos em questão. Revista Eletrônica de Educação, v.11, n.1, p.217-229, jan./maio, 2017.

SOUZA, L. G. Avaliação de políticas educacionais: contexto e conceitos em busca da avaliação pública. In: LORDÊLO, J.A.C.; DAZZANI, M.V. (orgs.). Avaliação educacional: desatando e reatando nós. Salvador: EDUFBA, 2009.

VEJA como vai funcionar o convênio para alunos e professores da rede estadual com o Sistema S. Seduc, Porto Alegre, 2017. Disponível em: < http:/ /www.educacao.rs.gov.br/ veja-como-vai-funcionar-o-convenio-para-alunos-e-professores-da-rede-estadual-com-osistema-s>. Acesso em 19 dez. 2017. 